\title{
Retinoic Acid Fails to Reverse Oligohydramnios-Induced Pulmonary Hypoplasia in Fetal Rats
}

\author{
CHUNG-MING CHEN, HSIU-CHU CHOU, LENG-FANG WANG, YAW-DONG LANG, AND CHING-YING YEH
}

\begin{abstract}
Department of Pediatrics [C.-M.C.], Department of Anatomy [H.-C.C.], Department of Biochemistry [L.-F.W.], Graduate Institute of Medical Sciences [Y.-D.L.], Department of Public Health [C.-Y.Y], College of Medicine, Taipei Medical University, Taipei 110, Taiwan
\end{abstract}

\begin{abstract}
All-trans retinoic acid (ATRA) stimulates plateletderived growth factor (PDGF)-A expression and enhances alveolarization in rat lungs. On d 16 of gestation, pregnant Sprague-Dawley rats were randomly assigned to either a retinoic acid group (intragastric ATRA at $10 \mathrm{mg} / \mathrm{kg}$ body weight) or a vehicle group. We punctured each amniotic sac, and fetuses in the opposite uterine horn served as controls. On d 21 of gestation, the fetuses were delivered by cesarean section. Rats subjected to oligohydramnios exhibited significantly lower lung weights and lung/body weight ratios, and ATRA had no effects on the body or lung weights of oligohydramnios-exposed rats. Lung PDGF-A and -B mRNA expression was significantly lower in oligohydramnios-exposed rats compared with control littermates of maternal vehicle-treated dams. Maternal retinoic acid treatment significantly increased PDGF-A and -B mRNA expression in control and oligohydramnios-exposed rats compared with all rats and oligohydramnios-exposed rats of maternal vehicletreated dams, respectively. Rats exposed to oligohydramnios exhibited a significantly lower generation of alveolar saccules than did control rats in the maternal retinoic acid- and vehicle-treated groups. In this model, maternal retinoic acid treatment showed no positive effects on oligohydramnios-induced pulmonary hypoplasia in the pseudoglandular stage. (Pediatr Res 62: 553-558, 2007)
\end{abstract}

$P^{\prime}$ ulmonary hypoplasia is common in the perinatal period and a significant cause of death in newborn infants $(1,2)$. Oligohydramnios is one of the most commonly associated abnormalities. Oligohydramnios may retard fetal lung growth and can result in pulmonary hypoplasia in experimental animals (3-5) and in human fetuses with prolonged rupture of the membranes (6). Currently, no specific therapies are clinically available to correct the lung hypoplasia in fetuses with oligohydramnios.

The mechanism that arrests lung development in the setting of oligohydramnios is not clear. Physical forces play important roles in regulating fetal lung growth and maturation $(7,8)$. The main physical force the lung experience is stretching produced by fetal breathing movements and lung fluids in the airspaces during normal lung development (9). Mechanical stretching may increase growth factor expression through intracellular signal transduction pathways (10). Plateletderived growth factor (PDGF) is important for alveogenesis

Received March 26, 2007; accepted June 17, 2007.

Correspondence: Chung-Ming Chen, M.D., Ph.D., Department of Pediatrics, Taipei Medical University Hospital, 252 Wu Hsing Street, Taipei 110, Taiwan; e-mail: cmchen@tmu.edu.tw

Supported by a grant from the National Science Council, Taiwan (NSC95-2314-B038-009). and angiogenesis of the normally developing lung (11). PDGFs are homodimers or heterodimers consisting of two distinct polypeptide chains (A and B), which can be dimerized via sulfhydryl bridges to form three bioactive isoforms (AA, $\mathrm{BB}$, and $\mathrm{AB}$ ) (12). Recently, we found pulmonary hypoplasia with reduced radial saccular counts and decreased PDGF-A and -B expression in oligohydramnios-exposed fetal rats (13). Liebeskind et al. (14) noted that all-trans retinoic acid (ATRA) might stimulate PDGF-A mRNA expression in cultured fetal and postnatal rat lung fibroblasts and in newborn rat lungs. Administration of ATRA, a metabolite of vitamin A, to newborn rats on $\mathrm{d} 4$ and 5 of life resulted in increased lung PDGF-A mRNA expression on $\mathrm{d} 6$. This study suggests that ATRA may influence alveolarization through a PDGFmediated mechanism. ATRA has also been reported to induce septation in a rat model of pharmacologically caused failure of septation (15). We hypothesized that retinoic acid may increase PDGF expression and enhance lung development in oligohydramnios-exposed fetal rats. The aim of this study was to evaluate the effects of maternal retinoic acid treatment on pulmonary hypoplasia induced by oligohydramnios in fetal rats.

\section{MATERIALS AND METHODS}

Animals. This study was approved by the Animal Care and Use Committees of Taipei Medical University and was performed with virgin and timed pregnant Sprague-Dawley rats. Pregnant dams were randomly assigned to either a retinoic acid group or vehicle group on gestational d 16. Each pregnant dam in the retinoic acid group and vehicle group was given a single dose of $3 \mathrm{~mL}$ ATRA (10 mg/kg body weight, Sigma Chemical Co., St. Louis, $\mathrm{MO}$ ) or an equal volume of the vehicle solution (ethanol:olive oil:water in 1:1:1 by volume) via an intragastric route without anesthesia (Fig. 1). ATRA was shielded from light at all times, and the solution was prepared on the day of administration. ATRA was administered on d 16 of gestation to precede the period when the fetal rat lung retinyl palmitate concentration rapidly increases to a peak on gestational d 17 (16). The dose was based on a study by Shenai and Chytil (17), who reported that a single dose of retinyl palmitate via maternal intragastric administration on gestational d 16 leads to a significant increase in fetal lung retinyl esters within $24 \mathrm{~h}$, and the effect persists until postnatal d 14. The dams were anesthetized with pentobarbital [50 mg/kg, intraperitoneally (i.p.)] $1 \mathrm{~h}$ after intragastric retinoic acid or vehicle administration. An abdominal midline incision was made, and the two uterine horns were exposed and kept moist with phosphate-buffered saline (PBS) (13). The uterine wall and fetal membranes of each amniotic sac in one horn were punctured using a 19-gauge needle and resulted in immediate visible leakage of amniotic fluid and a decrease in the size of the amniotic sac. Fetuses in the

Abbreviations: ATRA, all-trans retinoic acid; PDGF, platelet-derived growth factor 
Retinoic acid or vehicle on day 16 of gestation

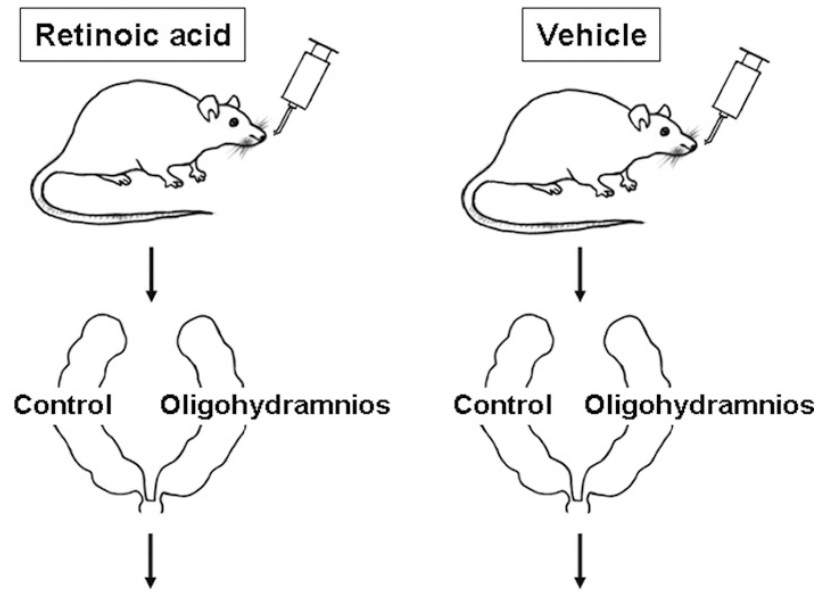

Delivered by cesarean section on day 21 of gestation

Figure 1. Schematic of the experimental design.

opposite uterine horn served as controls. The uterus was returned to the abdomen, and the abdominal incision was repaired in two layers with silk sutures. The dam was placed in an isolated cage and allowed to recover. On d 21 of gestation, the dams were anesthetized with pentobarbital $(50 \mathrm{mg} / \mathrm{kg}$, i.p.), and the fetuses were delivered by cesarean section. The fetuses were weighed and killed by pentobarbital $(100 \mathrm{mg} / \mathrm{kg}$, i.p.), a ventral midline incision was made, the lungs were dissected free and weighed, and results were expressed as the ratio (\%) of lung/body weights.

PDGF mRNA expression by real-time polymerase chain reaction (PCR). Total RNA was extracted from lung tissue that was ground into a powder in liquid nitrogen using the TRIzol Reagent (Invitrogen Life Technologies, Paisley, UK) according to the manufacturer's instructions. Reverse transcription was performed on $1 \mu \mathrm{g}$ of RNA with oligo-dT primers and avian myeloblastosis virus reverse transcriptase (Roche, Indianapolis, IN). Primer sequences for real-time PCR included PDGF-A sense 5'-AGGTGAGGTTAGAGGAGCAC-3', antisense 5'-TCGCTCTCTGTGACAAGG-3'; PDGF-B sense $5^{\prime}$-CACATTCTGGAGTCGAGTCG-3', antisense $5^{\prime}$-TCACCCGAGTTTGAGGTGTC-3'; 18S rRNA sense 5'-CGCCGCTAGAGGTGAAATTC-3', antisense $5^{\prime}$-CCAGTCGGCATCGTTTATGG-3'. The realtime PCR was performed using SYBR green PCR master mix (Applied Biosystems, Foster City, CA) on an ABI 7300 sequence detector. Samples were cycled for $15 \mathrm{~s}$ at $95^{\circ} \mathrm{C}$ and $60 \mathrm{~s}$ at $60^{\circ} \mathrm{C}$ for 40 cycles. Gene expression was quantitatively analyzed using the comparative $\mathrm{CT}(\Delta \mathrm{CT})$ method by ABI Prism 7000 SDS software, in which CT is the threshold cycle number (the minimum number of cycles needed before the product can be detected). The arithmetic formula for the $\Delta \mathrm{CT}$ method is the difference in threshold cycles for a target (PDGF) and an endogenous reference (housekeeping gene 18S rRNA). The amount of target normalized to an endogenous reference and relative to a calibration normalized to an endogenous reference is given by $2 \Delta \Delta \mathrm{CT}$. Values of the control + vehicle groups were normalized to a value of 1 , and values of other groups were normalized to these. Four samples were analyzed for each gene in each group.

Immunohistochemistry of PDGF. Immunohistochemical staining for PDGF-A and -B was performed on paraffin sections with immunoperoxidase visualization. After deparaffinization in xylene and rehydration in an alcohol series, sections were first preincubated for $1 \mathrm{~h}$ at room temperature in $0.1 \mathrm{M}$ PBS containing $10 \%$ normal goat serum and $0.3 \% \mathrm{H}_{2} \mathrm{O}_{2}$ to block endogenous peroxidase activity and nonspecific binding of the antibody before being incubated for $20 \mathrm{~h}$ at $4{ }^{\circ} \mathrm{C}$ with a mouse monoclonal antibody (MAb) against PDGF-AA and goat polyclonal antibody against PDGF-BB. Sections were then treated for $1 \mathrm{~h}$ at room temperature with biotinylated anti-mouse and anti-goat immunoglobulin G. This was followed by the reaction with the reagents from an $\mathrm{ABC}$ kit (Avidin-Biotin Complex, Vector Laboratories, Burlingame, CA) per the manufacturer's recommendations, and the reaction products were visualized by 3,3-diaminobenzidine, $0.003 \% \mathrm{H}_{2} \mathrm{O}_{2}$ in $0.5 \mathrm{M}$ Tris buffer ( $\mathrm{pH}$ 7.6) before the sections were mounted on gelatin-coated slides using Permount (Fisher Scientific, Pittsburgh, PA).

Quantification of PDGF-AA and PDGF-BB immunoreactivity. A minimum of four random lung fields of immunohistochemistry-stained sections per animal at $400 \times$ magnification were captured with a digital camera and imported into the computerized image analysis system Image-Pro Plus 5.1 for Windows. The automatic object counting and measuring process was used to quantify the immunoreactivity in the sections (18). We used the count/size function command to perform a cell number counting operation. This generated a percentage of positively stained cells, and the values were expressed as labeling index $(\%)$.

Morphologic analysis. For the morphologic studies, the lungs were removed and fixed in 10\% neutral buffered formalin. Serial lung sections were cut at a 4- $\mu \mathrm{m}$ thickness and stained with hematoxylin and eosin to observe the general morphology. We assessed the development of the lung parenchyma by counting the generation of alveolar saccules from the terminal bronchiole to the pleura in five to eight fetuses for each group (19). Five nonoverlapping microscopic fields per animal were chosen and photographed. The generation of alveolar saccules was counted by an observer who was blinded to the treatment group.

Statistical analysis. Body weight, lung weight, and lung/body weight ratio are expressed as the median (interquartile range), whereas other data are presented as the means \pm SEM. Analysis of difference among multiple groups was carried out by Kruskal-Wallis test, and significance was determined using Kruskal-Wallis test for multiple comparisons. The survival rate was compared using the Fisher exact test. Differences were considered significant at $p<$ 0.05 .

\section{RESULTS}

Six pregnant dams were used for this study. Three pregnant dams were treated with retinoic acid. Control fetuses were all alive at the time of the cesarean section. The survival rate of oligohydramnios-exposed fetuses was lower in the maternal vehicle-treated group. Five of $16(31.3 \%)$ and 12 of 30 $(40.0 \%)$ oligohydramnios-exposed fetuses were alive at the time of the cesarean section in maternal vehicle- and retinoic acid-treated groups, respectively.

Body weight, lung weight, and the lung/body weight ratio (\%). Effects of oligohydramnios and maternal retinoic acid treatment on the fetal body weight, lung weight, and lung/ body weight ratio (\%) are presented in Table 1 . Rats exposed to oligohydramnios exhibited significantly lower lung weights and lung/body weight ratios when compared with their control

Table 1. Body weight, lung weight, and the lung/body weight ratio in control and oligohydramnios-exposed rats

\begin{tabular}{lrlll}
\hline \multicolumn{1}{c}{ Treatment } & $n$ & \multicolumn{1}{c}{ Body weight $(\mathrm{g})$} & \multicolumn{1}{c}{ Lung weight $(\mathrm{g})$} & Lung/body weight $(\%)$ \\
\hline Control + vehicle & 12 & $3.65(3.45-3.73)$ & $0.11(0.10-0.12)$ & $3.08(2.79-3.24)$ \\
Oligohydramnios + vehicle & 5 & $3.54(3.07-3.60)$ & $0.07(0.06-0.10)^{*}$ & $2.26(1.95-2.85)^{*}$ \\
Control + RA & 12 & $3.99(3.89-4.20) \dagger$ & $0.12(0.11-0.13)$ & $3.00(2.77-3.22)$ \\
Oligohydramnios + RA & 12 & $3.86(3.51-4.00) * \$$ & $0.09(0.87-0.11) \S$ & $2.59(2.17-2.88) \|$ \\
\hline
\end{tabular}

Values are expressed as the median (interquartile range). RA, retinoic acid.

$* p<0.05$.

$\dagger p<0.01$ compared with the oligohydramnios + vehicle and control + vehicle group, respectively.

$\ddagger p<0.05$.

$\S p<0.001$ compared with the control + vehicle or control + RA group.

$\| p<0.01$. 
littermates. Maternal retinoic acid treatment had no effects on the body or lung weights of oligohydramnios-exposed rats. Maternal retinoic acid treatment significantly increased the body weight in control and oligohydramnios-exposed rats compared with the control + vehicle and oligohydramnios + vehicle groups.

Lung PDGF mRNA expression. Effects of oligohydramnios and maternal retinoic acid treatment on PDGF-A and -B mRNA expression are presented in Figures 2 and 3, respectively. PDGF-A and -B mRNA expression was significantly lower in oligohydramnios-exposed rats compared with control littermates of maternal vehicle-treated dams. Maternal retinoic acid treatment significantly increased PDGF-A mRNA expression in control and oligohydramnios-exposed rats when compared with the control + vehicle and oligohydramnios + vehicle groups (Fig. 2). Maternal retinoic acid treatment significantly increased PDGF-B mRNA expression in control and oligohydramnios-exposed rats when compared with the oligohydramnios + vehicle group (Fig. 3).

Immunohistochemistry of PDGF. Immunoreactivity of PDGF-AA (Fig. $4 A-D$ ) and PDGF-BB (Fig. $5 A-D$ ) was mainly detected in airway epithelial and some mesenchymal

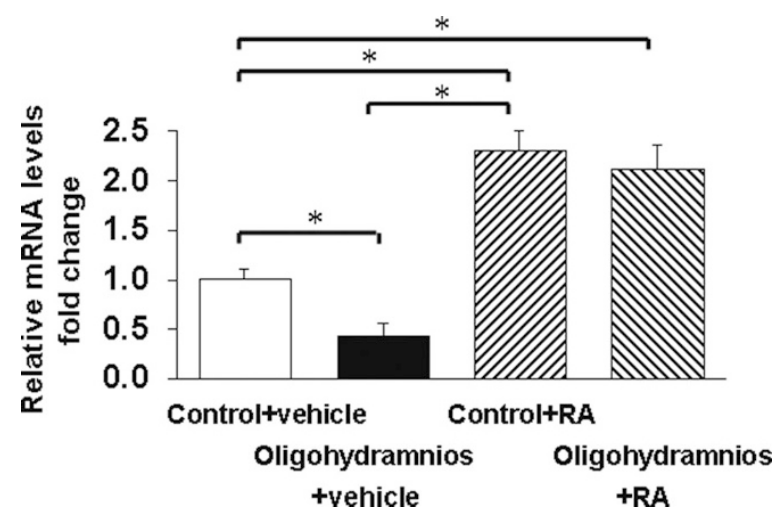

Figure 2. PDGF-A mRNA expression in fetal rat lungs. PDGF-A mRNA expression was significantly lower in oligohydramnios-exposed rats (ם) compared with control littermates $(\square)$. Maternal retinoic acid treatment significantly increased PDGF-A mRNA expression in the control $(\mathbb{Z})$ and oligohydramnios-exposed $(\mathbb{N})$ rats compared with untreated control $(\square)$ and oligohydramnios-exposed $(\square)$ rats. $(* p<0.05)$.

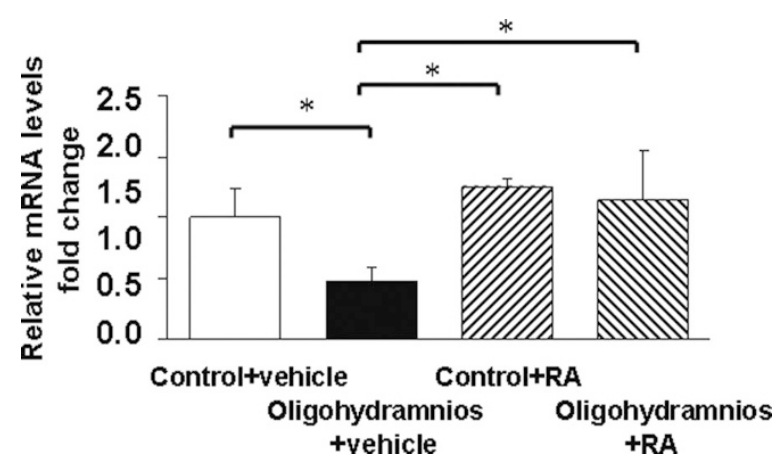

Figure 3. PDGF-B mRNA expression in fetal rat lungs. Oligohydramniosexposed rats $(\square)$ exhibited significantly lower PDGF-B mRNA expression compared with control rats $(\square)$ from maternal vehicle-treated dams. Maternal retinoic acid treatment significantly increased PDGF-B mRNA expression in the control $(\mathbb{Z})$ and oligohydramnios-exposed $(\mathbb{N})$ rats compared with untreated oligohydramnios-exposed rats $(\square)(* p<0.05)$. cells, and the immunoreactivity was reduced in oligohydramnios-exposed rats. In retinoic acid-treated rats, PDGF-AA and -BB immunoreactivity significantly increased compared with oligohydramnios-exposed rats (Fig. $4 E$ and $E$ ). Changes in the immunoreactivity of PDGF-AA and -BB in all four groups were similar to those in their mRNA expression.

Morphologic analysis. The histologic appearance of hematoxylin and eosin-stained lungs is illustrated in Figure 6. Representative lung sections depict a thicker interstitium and fewer saccules in oligohydramnios-exposed rats in the maternal retinoic acid- or vehicle-treated groups (Fig. 6A). The generation of alveolar saccules was significantly lower in oligohydramnios-exposed rats than that of control rats in the maternal retinoic acid- and vehicle-treated groups (Fig. 6B).
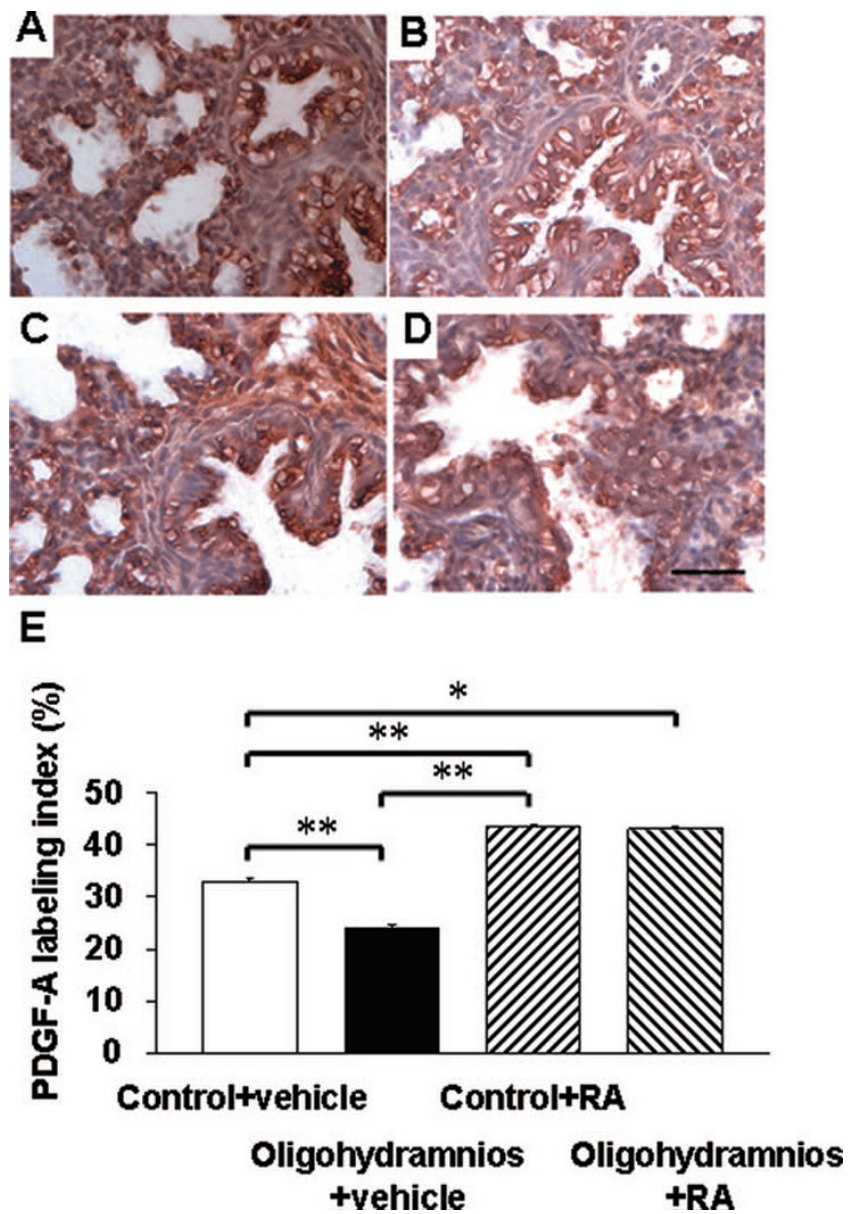

Figure 4. Immunohistochemical staining for PDGF-AA in lung sections $(\times 400)$. Positive staining is shown in brown. Representative fields from control + vehicle $(A)$, oligohydramnios + vehicle $(B)$, control + RA $(C)$, and oligohydramnios + RA $(D)$. The PDGF-AA protein was localized mainly in airway epithelial and some mesenchymal cells, and the immunoreactivity was reduced in oligohydramnios-exposed $(B, D)$ rats. In retinoic acid-treated $(C$, $D$ ) rats, PDGF-AA immunoreactivity increased compared with the control $(A)$ and oligohydramnios-exposed $(B)$ rats from maternal vehicle-treated groups. Bar $=50 \mu \mathrm{m}$. $(E)$ Quantitative analysis of PDGF-AA immunoreactivity in untreated control $(\square)$, oligohydramnios-exposed $(\square)$, maternal retinoic acidtreated control $(\mathbb{Z})$, and oligohydramnios-exposed $(\mathbb{N})$ rats. Maternal retinoic acid treatment significantly increased PDGF-AA immunoreactivity in control and oligohydramnios-exposed rats compared with the control + vehicle and oligohydramnios + vehicle groups $(* p<0.05 ; * * p<0.01)$. 


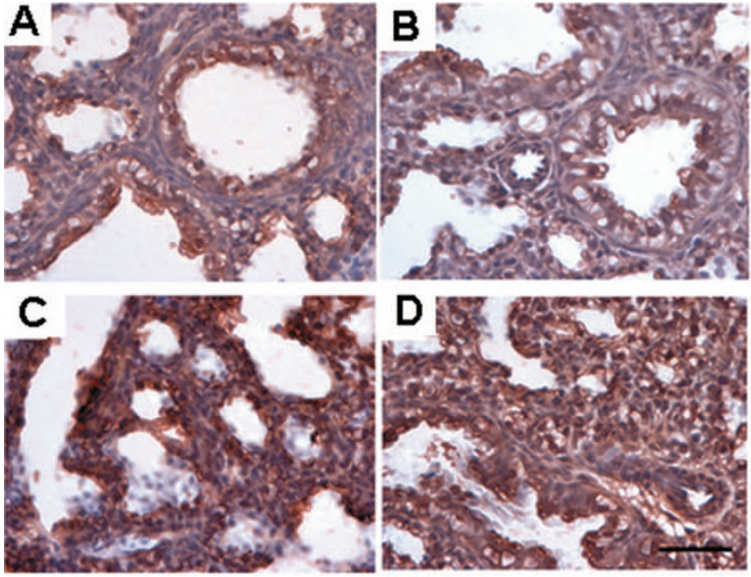

E

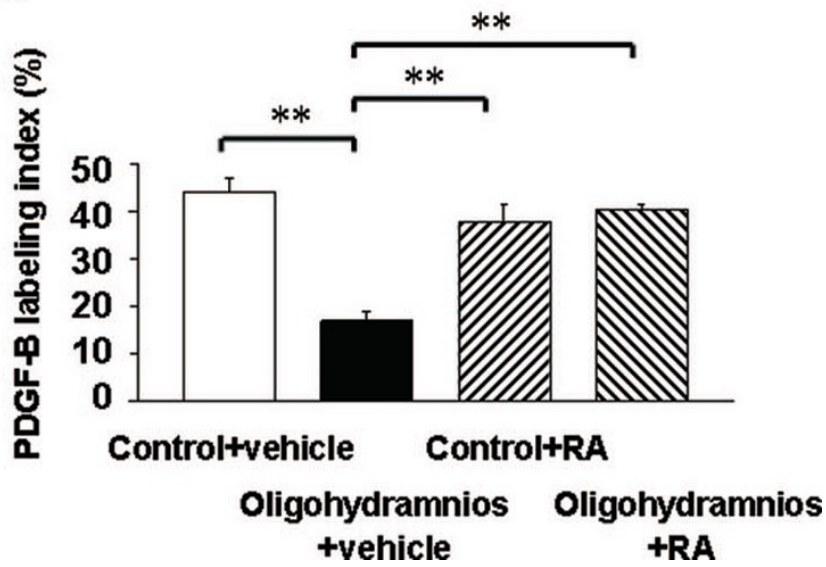

Figure 5. Immunohistochemical staining for PDGF-BB in lung sections $(\times 400)$. Positive staining is shown as brown. Representative fields from control + vehicle $(A)$, oligohydramnios + vehicle $(B)$, control + RA $(C)$, and oligohydramnios + RA $(D)$. The PDGF-BB protein was localized mainly in airway epithelial cells. Low PDGF-BB immunoreactivity was detected in oligohydramnios-exposed $(B)$ rats with maternal vehicle treatment. Maternal retinoic acid treatment increased PDGF-BB immunoreactivity of oligohydramnios-exposed $(D)$ rats to the level of control $(C)$ rats. Bar $=50 \mu \mathrm{m}$. $(E)$ Quantitative analysis of PDGF-BB immunoreactivity in untreated control $(\square)$, oligohydramnios-exposed $(\square)$, maternal retinoic acid-treated control $(\mathbb{Z})$, and oligohydramnios-exposed $(\mathbb{N})$ rats. Maternal retinoic acid treatment significantly increased PDGF-BB immunoreactivity in control and oligohydramnios-exposed rats when compared with the oligohydramnios + vehicle group $(* * p<0.01)$.

\section{DISCUSSION}

The effects of maternal retinoic acid treatment on lung development and PDGF expression in oligohydramniosexposed fetal rats are largely unknown. In the present study, late gestational exposure of fetal rats to oligohydramnios for $5 \mathrm{~d}$ was found to have produced pulmonary hypoplasia and decreased lung PDGF-A and -B expression. Concomitant maternal retinoic acid treatment at a dose of $10 \mathrm{mg} / \mathrm{kg}$ increased PDGF-A and -B expression but did not enhance fetal lung development as evidenced by lung weight and the generation of alveolar saccules. These results suggest that PDGF may not be the major determinant of lung development in experimental oligohydramnios.

No oligohydramnios model is perfect. Surgical drainage is valid for a large-animal model for technical reasons. Report in
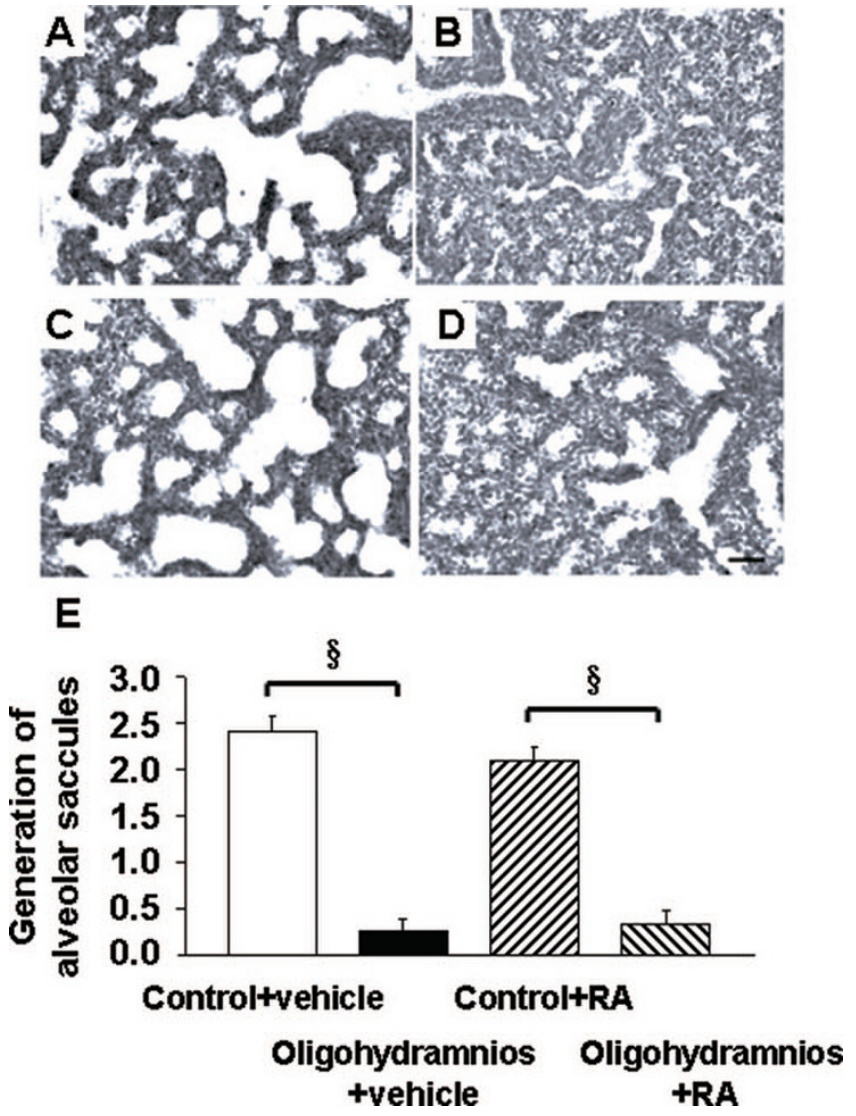

Figure 6. Histologic analysis of retinoic acid treatment on lung development $(\times 200)$. Representative fields from control + vehicle $(A)$, oligohydramnios + vehicle $(B)$, control + RA $(C)$, and oligohydramnios + RA $(D)$. Oligohydramnios-exposed $(B, D)$ rats exhibited a thicker interstitium, fewer and less advanced saccules, and fewer bronchial passageways compared with control animals $(A, C)$. Bar $=50 \mu \mathrm{m}$. $(E)$ The generation of alveolar saccules was

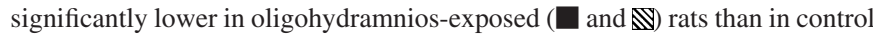
$(\square$ and $\mathbb{Z}$ ) rats in maternal retinoic acid- and vehicle-treated groups $(\S p<$ $0.001)$

the literature support the use of rodents for studying oligohydramnios because their relative timing of alveolarization resembles human lung development. Collins et al. (20) produced oligohydramnios from d 45 to 50 of gestation in the guinea pig and found fewer saccules and a decreased gasexchange surface area. Oligohydramnios may retard fetal lung growth and result in pulmonary hypoplasia (3-5). Pulmonary hypoplasia was defined as underdevelopment of the lungs with a low lung weight for a given body weight. The general manifestation of retarded lung growth-induced by oligohydramnios is reduced lung weight and lung/body weight ratio (3-5). In the present study, we produced oligohydramnios on d 16 of gestation and found significant reductions in lung weight and lung/body weight ratio and lung development on $\mathrm{d}$ 21 of gestation. Although we did not measure dry lung weight or lung DNA content, oligohydramnios did produce pulmonary hypoplasia based on lung weight and lung/body weight ratio and histologic findings.

The effects of maternal retinoic acid administration on normal fetal body and lung weights have rarely been reported. In this study, maternal retinoic acid treatment significantly increased the body weight of control and oligohydramnios- 
exposed rats compared with control and oligohydramniosexposed rats of maternal vehicle-treated dams and had no significant effects on lung weights. These data on lung weight are consistent with those of Baptista et al. (21) who demonstrated that late antenatal administration of vitamin $\mathrm{A}$ on $\mathrm{d}$ 18.5 of gestation did not affect the lung growth of fetuses delivered on $\mathrm{d} 22$ of gestation.

Lung development is a very complex and tightly controlled process. It is achieved through branching of the airways to form the conducting respiratory airways and by septation of the saccules into alveoli. Branching begins during the embryonic stage (d 11 and 13), peaks in the pseudoglandular stage (d 14 and18), and lasts until the canalicular stage (d 19 and 20). The molecular basis of lung branching morphogenesis encompasses interactions among transcription factors, growth factors, and the extracellular matrix (22). PDGF is a powerful stimulator of fibroblast proliferation and collagen production (23). Han et al. (24) reported that both PDGF and its receptors are present in the fetal rat lung. PDGF exists as a homodimer or heterodimer consisting of two polypeptide chains, denoted $\mathrm{A}$ and $\mathrm{B}$, which can be dimerized via sulfhydryl bridges to form three bioactive isoforms (12). By using antisense PDGF-A oligonucleotides and antisense PDGF-B oligodeoxynucleotides in an embryonic rat lung explant culture, Souza et al. $(25,26)$ found that PDGF-AA and PDGF-BB play critical roles in early lung branching morphogenesis and lung growth, respectively. Results of our in vivo study showed that oligohydramnios-exposed rats from vehicle-treated dams exhibited down-regulation of PDGF expression, pulmonary hypoplasia, and reduced generation of alveolar saccules. These results were compatible with in vitro analyses by Souza et al. $(25,26)$.

Retinoic acid has been shown to stimulate PDGF-A mRNA expression in cultured fetal and postnatal rat lung fibroblasts and newborn rat lungs (14). In our rat model, ATRA increased whole-lung PDGF-A and -B expression, but it failed to stimulate lung growth as measured by lung weight and the generation of alveolar saccules. These contrasting outcomes are likely to be related to differences in the stage of lung development and the timing and duration of the administration of ATRA. The administration of ATRA to pregnant rats results in the rapid transfer across the placenta to the fetuses (27). Lung retinyl ester was increased in neonatal rats treated with ATRA and retinyl ester storage granules were increased by exogenous ATRA in cultured lipid interstitial cells $(28,29)$. RA exerts its effects through nuclear retinoic acid receptors, which are present in the fetal rat lung (30). The retinoic acid receptors may interact with retinoic acid response elements to activate transcription of the target gene PDGF (31).

Retinoic acid influences cell programming and differentiation during early lung development, and its activity is reduced during airway branching (32). Branching morphogenesis is inhibited when retinoic acid signaling was activated by exogenous retinoic acid in vitro and in retinoic acid receptor transgenic mice $(33,34)$. Blocking retinoic acid signaling by a pan-retinoic acid receptor antagonist increases explant bud formation, whereas treatment with retinoic acid reduces explant bud formation of fetal mice lung in the pseudoglandular stage (35). Our studies and those of others indicate that there is a stage-specific requirement for retinoic acid during lung development, and retinoic acid treatment should be applied cautiously.

In conclusion, this study shows that experimental oligohydramnios on $\mathrm{d} 16$ of gestation produces pulmonary hypoplasia and decreases PDGF expression on d 21 of gestation in fetal rats. Although maternal retinoic acid treatment increased lung PDGF-A and -B expression, it did not exert positive effects on pulmonary hypoplasia induced by oligohydramnios. This study does not support the use of maternal retinoic acid to prevent or ameliorate oligohydramnios-induced pulmonary hypoplasia in the pseudoglandular stage. Further study is required to determine the effects of the dose and timing of administration of retinoic acid on oligohydramnios-induced pulmonary hypoplasia.

\section{REFERENCES}

1. Wigglesworth JS, Desai R 1982 Is fetal respiratory function a major determinant of perinatal survival? Lancet 1:264-267

2. Husain AN, Hessel RG 1993 Neonatal pulmonary hypoplasia: an autopsy study of 25 cases. Pediatr Pathol 13:475-484

3. Moessinger AC, Bassi GA, Ballantyne G, Collins MH, James LS, Blanc WA 1983 Experimental production of pulmonary hypoplasia following amniocentesis and oligohydramnios. Early Hum Dev 8:343-350

4. Kitterman JA, Chapin CJ, Vanderbilt JN, Porta NF, Scavo LM, Dobbs LG, Ertsey R, Goerke J 2002 Effects of oligohydramnios on lung growth and maturation in the fetal rat. Am J Physiol Lung Cell Mol Physiol 282:L431-L439

5. Blachford KG, Thurlbeck WM 1987 Lung growth and maturation in experimental oligohydramnios in the rat. Pediatr Pulmonol 3:328-333

6. Thibeault DW, Beatty EC, Hall RT, Bowen SK, O'Nell DH 1985 Neonatal pulmonary hypoplasia with premature rupture of fetal membranes and oligohydramnios. J Pediatr 107:273-277

7. Harding R, Hooper SB 1996 Regulation of lung expansion and lung growth before birth. J Appl Physiol 81:209-224

8. Joe P, Wallen LD, Chapin CJ, Lee CH, Allen L, Han VK, Dobbs LG, Hawgood S, Kitterman JA 1997 Effects of mechanical factors on growth and maturation of the lung in fetal sheep. Am J Physiol 272:L95-L105

9. Kitterman JA 1996 The effects of mechanical forces on fetal lung growth. Clin Perinatol 23:727-740

10. Liu M, Tanswell AK, Post M 1999 Mechanical force-induced signal transduction in lung cells. Am J Physiol 277:L667-L683

11. Lindahl P, Bostrom H, Karlsson L, Hellstrom M, Kalen M, Betsholtz C 1999 Role of platelet-derived growth factors in angiogenesis and alveogenesis. Curr Top Pathol 93:27-33

12. Ross R 1989 Platelet-derived growth factor. Lancet 1:1179-1182

13. Chen CM, Wang LF, Chou HC, Lang YD 2007 Oligohydramnios decreases plateletderived growth factor expression in fetal rat lungs. Neonatology 92:187-193

14. Liebeskind A, Srinivasan S, Kaetzel D, Bruce M 2000 Retinoic acid stimulates immature lung fibroblast growth via a PDGF-mediated autocrine mechanism. Am J Physiol Lung Cell Mol Physiol 279:L81-L90

15. Massaro GD, Massaro D 2000 Retinoic acid treatment partially rescues failed septation in rats and in mice. Am J Physiol Lung Cell Mol Physiol 278:L955-L960

16. Masuyama H, Hiramatsu Y, Kudo T 1995 Effect of retinoids on fetal lung development in the rat. Biol Neonate 67:264-273

17. Shenai JP, Chytil F 1990 Effect of maternal vitamin-A administration on fetal lung vitamin-A stores in the perinatal rat. Biol Neonate 58:318-325

18. Lu G, Liao J, Yang G, Reuhl KR, Hao X, Yang CS 2006 Inhibition of adenoma progression to adenocarcinoma in a 4-(methylnitrosamino)-1-(3-pyridyl)-1butanone-induced lung tumorigenesis model in $\mathrm{A} / \mathrm{J}$ mice by tea polyphenols and caffeine. Cancer Res 66:11494-11501

19. Maltais F, Seaborn T, Guay S, Piedboeuf B 2003 In vivo tracheal occlusion in fetal mice induces rapid lung development without affecting surfactant protein $\mathrm{C}$ expression. Am J Physiol Lung Cell Mol Physiol 284:L622-L632

20. Collins MH, Moessinger AC, Kleinerman J, James LS, Blanc WA 1986 Morphometry of hypoplastic fetal guinea pig lungs following amniotic fluid leak. Pediatr Res 20:955-960

21. Baptista MJ, Melo-Rocha G, Pedrosa C, Gonzaga S, Teles A, Estevao-Costa J, Areias JC, Flake AW, Leite-Moreira AF, Correia-Pinto J 2005 Antenatal vitamin A administration attenuates lung hypoplasia by interfering with early instead of late determinants of lung underdevelopment in congenital diaphragmatic hernia. J Pediatr Surg 40:658-665

22. Roth-Kleiner M, Post M 2005 Similarities and dissimilarities of branching and septation during lung development. Pediatr Pulmonol 40:113-134

23. Ross R, Raines EW, Bowen-Pope DF 1986 The biology of platelet-derived growth factor. Cell 46:155-169

24. Han RN, Mawdsley C, Souza P, Tanswell AK, Post M 1992 Platelet-derived growth factors and growth-related genes in rat lung. III. Immunolocalization during fetal development. Pediatr Res 31:323-329 
25. Souza P, Kuliszewski M, Wang J, Tseu I, Tanswell AK, Post M 1995 PDGF-AA and its receptor influence early lung branching via an epithelial-mesenchymal interaction. Development 121:2559-2567

26. Souza P, Sedlackova L, Kuliszewski M, Wang J, Liu J, Tseu I, Liu M, Tanswell AK, Post M 1994 Antisense oligodeoxynucleotides targeting PDGF-B mRNA inhibit cell proliferation during embryonic rat lung development. Development 120:2163-2173

27. Collins MD, Tzimas G, Burgin H, Hummler H, Nau H 1995 Single versus multiple dose administration of all-trans-retinoic acid during organogenesis: differential metabolism and transplacental kinetics in rat and rabbit. Toxicol Appl Pharmacol 130:9-18

28. Ross AC, Ambalavanan N, Zolfaghari R, Li NQ 2006 Vitamin A combined with retinoic acid increases retinol uptake and lung retinyl ester formation in a synergistic manner in neonatal rats. J Lipid Res 47:1844-1851

29. Dirami G, Massaro GD, Clerch LB, Ryan US, Reczek PR, Massaro D 2004 Lung retinol storing cells synthesize and secrete retinoic acid, an inducer of alveolus formation. Am J Physiol Lung Cell Mol Physiol 286:L249-L256
30. Grummer MA, Thet LA, Zachman RD 1994 Expression of retinoic acid receptor genes in fetal and newborn rat lung. Pediatr Pulmonol 17:234-238

31. Kaetzel DM 2003 Transcription of the platelet-derived growth factor A-chain gene. Cytokine Growth Factor Rev 14:427-446

32. Warburton D, Zhao J, Berberich MA, Bernfield M 1999 Molecular embryology of the lung: then, now, and in the future. Am J Physiol 276:L697-L704

33. Mollard R, Ghyselinck NB, Wendling O, Chambon P, Mark M 2000 Stagedependent responses of the developing lung to retinoic acid signaling. Int J Dev Biol 44:457-462

34. Wongtrakool C, Malpel S, Gorenstein J, Sedita J, Ramirez MI, Underhill TM, Cardoso WV 2003 Down-regulation of retinoic acid receptor alpha signaling is required for sacculation and type I cell formation in the developing lung. J Biol Chem 278:46911-46918

35. Chazaud C, Dolle P, Rossant J, Mollard R 2003 Retinoic acid signaling regulates murine bronchial tubule formation. Mech Dev 120:691-700

\section{Erratum}

In the article, "The Ocular Anomalies in a Cystinosis Animal Model Mimic Disease Pathogenesis" by Vasiliki Kalatzis et al. (Pediatr Res 62:156-162), Fig. 1 was typeset incorrectly. The correct Fig. 1, appears below. The publisher regrets the error.
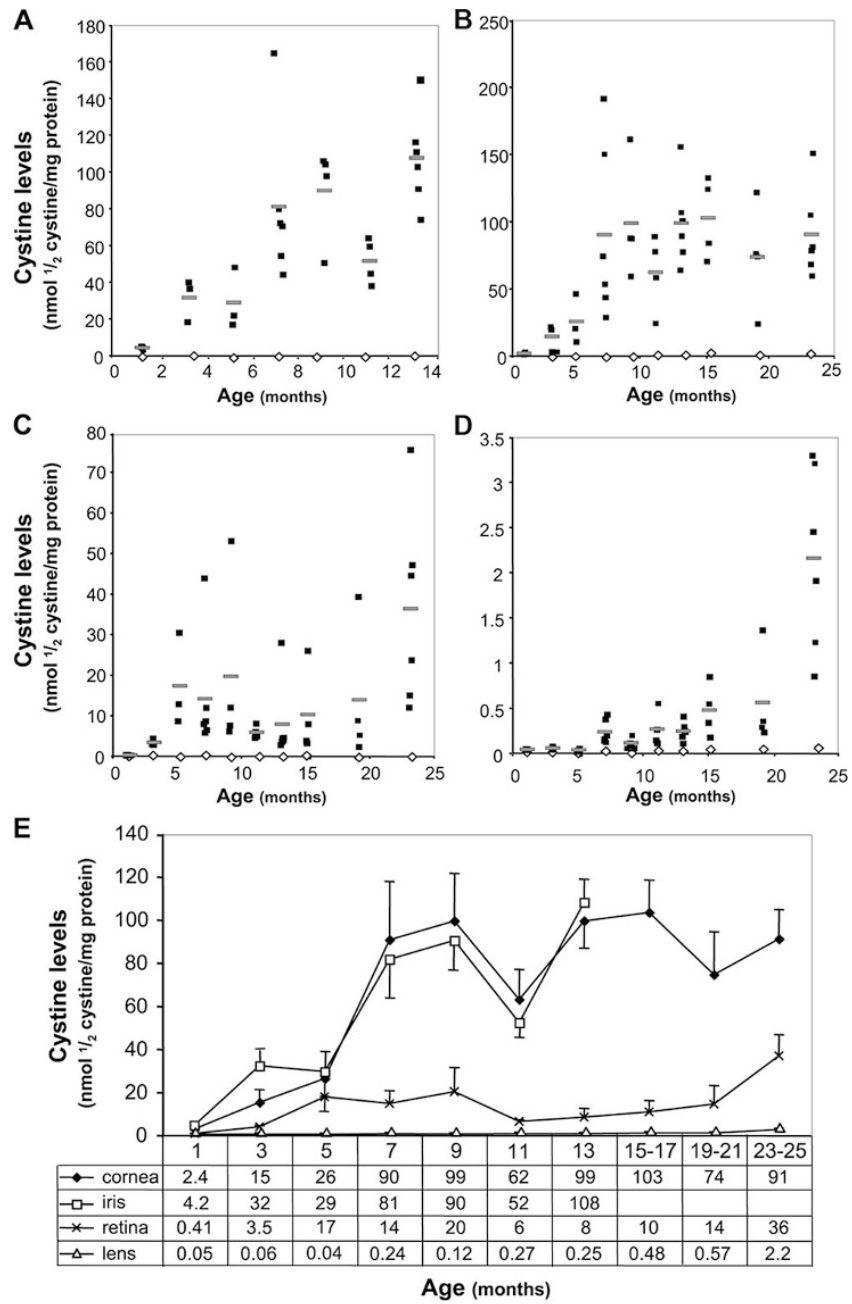

Figure 1. $\bullet \bullet \bullet$ 